\title{
Right pneumonectomy and thoracoplasty followed by coronary artery bypass grafting and mitral valve replacement
}

\author{
I. El-Hamamsy, MD, ${ }^{*}$ L-M. Stevens, MD, ${ }^{*}$ L. P. Perrault, MD, PhD, and M. Carrier, MD, Montreal, Quebec, Canada
}

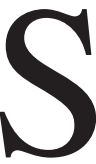

imultaneous cardiac surgery and pulmonary resection for lung cancer has been proposed by several authors. ${ }^{1}$ Furthermore, lung resection continues to be used in some cases of multi-drug resistant tuberculosis ${ }^{2}$ and also to treat complicated lesions in cases of sequelar forms of pulmonary tuberculosis. ${ }^{3}$ Right pneumonectomy and thoracoplasty were used in the 1950s for active tuberculosis. These operations caused significant chest deformity and impairment of pulmonary function tests. Three long-term survivors of such operations requiring cardiac surgery were recently encountered. This report discusses cardiac procedures after right pneumonectomy and thoracoplasty.

\section{Clinical Summaries}

PATIENT 1. A 65-year-old woman with severe mitral and tricuspid insufficiency was evaluated for surgical intervention. She had undergone a right pneumonectomy and thoracoplasty in 1952 for active tuberculosis. Deformity of the right side of the chest was obvious on physical examination, and pulmonary function test results were severely abnormal (Table 1). Chest physiotherapy was started before the operation. Through a median sternotomy, she underwent mitral valve replacement and a tricuspid annuloplasty. Extensive decalcification of the mitral anulus was necessary. There were no dense intrapericardial adhesions, and a standard left atrial approach was used. She was extubated 10 hours after the operation. Five days later, a chest tube was inserted for an iatrogenic pneumothorax on the left side after implantation of a permanent pacemaker. The patient fully recovered and was discharged in excellent condition 20 days after the operation.

PATIENT 2. A 71-year-old woman with 3-vessel disease was evaluated for surgical intervention. She had undergone a right pneumonectomy and thoracoplasty in 1953 for active tuberculosis (Figure 1). Deformity of the right side of the chest was obvious, and pulmonary function test results were severely abnormal (Table 1). Chest physiotherapy was started preoperatively. She underwent off-pump triple coronary artery bypass grafting (CABG) by using saphenous vein grafts through a median sternotomy. She was

\footnotetext{
From the Research Center, Montreal Heart Institute, Montreal, Quebec, Canada.

Received for publication June 4, 2002; accepted for publication June 13 2002.

*The first two authors have contributed equally to this work.

Address for reprints: L. P. Perrault, MD, PhD, Research Center, Montreal Heart Institute, 5000 Bélanger Street East, Montréal, Québec H1T 1C8, Canada (E-mail: lpperrau@icm.umontreal.ca).

J Thorac Cardiovasc Surg 2003;125:215-6

Copyright $\odot 2003$ by The American Association for Thoracic Surgery

$0022-5223 / 2003 \$ 30.00+0$

doi: $10.1067 / \mathrm{mtc} .2003 .126$
}

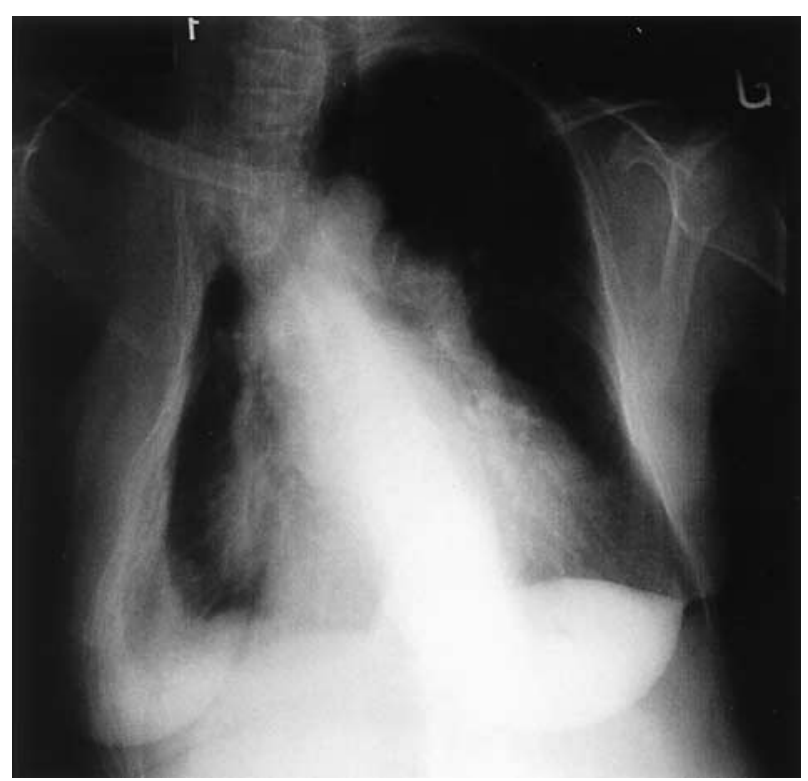

Figure 1. Chest radiograph of patient 2 showing a right pneumonectomy and thoracoplasty.

extubated 18 hours after the operation and was discharged in excellent condition 6 days later.

PATIENT 3. A 73-year-old man with 3-vessel disease was evaluated for surgical intervention. He had a right thoracoplasty in 1952 and subsequently had a right fibrothorax. Pulmonary function test results were severely abnormal (Table 1). Through a median sternotomy, he underwent successful off-pump triple CABG by using the internal thoracic artery and saphenous vein grafts. The left lung was bulging into the right hemithorax. He was extubated 16 hours after the operation. The patient was discharged in excellent condition 11 days later and was doing well 3 months after the operation.

\section{Comments}

The combination of right pneumonectomy and thoracoplasty causes significant chest deformity and impairment of respiratory function tests. Surgical approach to the heart and functional lung reserve are of concern when cardiac surgery is planned.

We used a standard median sternotomy in those patients and, to our surprise, the exposure for mitral valve surgery and for $\mathrm{CABG}$ were excellent, except for a slight deviation of the heart in the left chest cavity. Despite severely abnormal preoperative pulmonary function test results, those patients fully recovered after the operation. Patient 1 showed the effect of an iatrogenic pneumothorax in prolonging functional recovery and hospital stay. 
TABLE 1. Preoperative pulmonary function tests

\begin{tabular}{lcc}
\hline & FVC (L) & FEV $_{\mathbf{1}}(\mathbf{L} / \mathbf{s})$ \\
\hline Patient 1 & $1.37(44 \%)$ & $0.86(36 \%)$ \\
Patient 2 & $0.75(27 \%)$ & $0.60(28 \%)$ \\
Patient 3 & $1.93(47 \%)$ & $1.29(44 \%)$
\end{tabular}

$F V C$, Forced vital capacity; $F E V_{1}$, forced expiratory volume in 1 second.

In patient 2 the chest cavity was left intact by using only saphenous vein grafts, whereas we also used the internal thoracic artery in patient 3 with similar results. Danton and colleagues ${ }^{1}$ also reported good results in using off-pump CABG combined with pneumonectomy for cancer in 2 patients. Both patients were extubated early, and there were no reported adverse respiratory complications.
In conclusion, use of standard median sternotomy to access the heart, intensive respiratory therapy, and off-pump techniques, when applicable, should ensure a successful result in approaching patients who have undergone previous right pneumonectomy and thoracoplasty.

\section{References}

1. Danton MHD, Anikin V, McManus KG, McGuigan JA, Campalani G. Simultanous cardiac surgery with pulmonary resection: presentation of series and review of literature. Eur J Cardiothorac Surg. 1998;13:667-72.

2. Pomerantz BJ, Cleveland JC, Olson HK, Pomerantz M. Pulmonary resection for multi-drug resistant tuberculosis. $J$ Thorac Cardiovasc Surg. 2001;121:448-53.

3. Souilamas R, Riquet M, Barthes FP, Chehab A, Capuani A, Faure E. Surgical treatment of active and sequelar forms of pulmonary tuberculosis. Ann Thorac Surg. 2001;71:443-7. 